\title{
A new CGMW map released: The Seismotectonic Map of the World, five millennia of earthquakes around the world
}

The Commission for the Geological Map of the World (CGMW), an IUGS affiliated body, has just published (end of May 2002) the first edition of the Seismotectonic Map of the World. The scale $(1: 25,000,000)$, projection (main map: Mercator; poles: stereographic) and format $(2 \mathrm{~m} \times 1 \mathrm{~m})$ are identical to those of the Commission's recently published 2nd edition of the Geological Map of the World (2000).

This new map is a co-publication of CGMW and UNESCO. Dr. A. Haghipour, CGMW Vice-President for the Middle East (and former President of the Geological Survey of Iran), coordinated the realization of the map in conjunction with an international Scientific Committee that included Profs. R. Madariaga, Ecole Normale Supérieure, Paris, France; R. Funiciello, Università Roma III, Italy; N.N. Ambraseys, Imperial College, London, U.K.; J.P. Cadet, Université P. et M. Curie, Paris, France; H. Kato, Geological Survey of Japan, Tsukuba; L. Whiteside, NOAA, Boulder, Colo., USA.

\section{Cartographic guidelines}

This map is the result of the compilation of worldwide seismic data spanning five millennia, provided by historical (reaching as back as the 3rd millennium BC) and instrumental data, plotted on a base representing a schematic global tectono-structural pattern that includes both continental (Precambrian shields, Phanerozoic orogens and basins) and oceanic areas (age of the basaltic basement, structural features and anomalous oceanic crust). For this background, relatively light colours have been used so as to facilitate the legibility of the seismic symbols, which represent the gist of the map. The age of the oceanic crust is shown by a gradation of colours ranging from warmer hues for younger crust to colder ones for older crust.

Plate boundaries with spreading axes (oceanic accretionary ridges), convergence zones (subduction, collision), and transform faults (strike-slip motion) are highlighted to provide a clear view of the present-day plate tectonics framework.

Different types of major fault (thrust/reverse, strike-slip/transform, normal/dip-slip, and unspecified) are also indicated. Thick lines represent faults that are currently active or within present-day mobile or deformation zones, particularly at plate or block boundaries, and major faults possibly active during the Quaternary and/or capable of reactivation; dashed lines represent concealed or inferred faults.

For active strike-slip and major transform faults, the approximate horizontal sense of motion and displacement rate (mm/year) are indicated where known. Similarly, most present-day plate kinematics are shown by relative plate motion vectors and velocities ( $\mathrm{mm} /$ year), and by half spreading rates ( $\mathrm{mm} /$ year) along axes of active oceanic accretion. Where known, extinct spreading axes are also shown.

Significant maximum horizontal stress orientations (within $\pm 10^{\circ}-15^{\circ}$ for 302 locations) are shown by a symbol coloured according to the respective stress regime: brown for normal faulting regimes $\left(S_{V}>S_{H \text { max }}>S_{h}\right.$ min $)$, green for strike-slip faulting regimes $\left(\mathrm{S}_{\mathrm{H} \max }>\mathrm{S}_{\mathrm{V}}>\mathrm{S}_{\mathrm{h} \min }\right)$, pink for thrust faulting regimes $\left(\mathrm{S}_{\mathrm{H} \max }>\right.$ $\mathrm{S}_{\mathrm{h} \text { min }}>\mathrm{S}_{\mathrm{V}}$ ) and black for unknown stress regimes.

In order to avoid overloading the map with an excessive number of earthquake locations, it has been decided to plot only events with a magnitude $\geq 6.0$ (on the Richter scale) or an intensity $\geq$ VIII ${ }^{*}$ (on the 12 grades MSK scale) when no magnitude record was available, as is - of course - the case for historical events (before AD 1900). In the latter case, the seismic events have been ranked on the basis of the estimated intensity. As a matter of fact, the number of earthquakes known over the past 5,000 years (from the third millennium $\mathrm{BC}$ to the beginning of the third millennium $\mathrm{AD}$ ) amount to some 5 million of which approximately 120,000 events were of magnitude $\geq 5$, including the 18,068 events of magnitude $\geq 6.0$ tabulated after elimination of duplicate and doubtful events.

In addition, 792 main Holocene and present-day active volcanoes (including some submarine ones, although none related to spreading axes) representing the selection plotted on the Geological Map of the World (2000) from the Volcanoes of the World (Simkin and Siebert, Smithsonian Institution, 1994) are represented respectively by small and medium brown asterisks. A distinction is made between volcanoes whose last known or probable eruption occurred from 10,000 years BP to AD 1 (325 volcanoes) and those whose last known eruption occurred during the last 2000 years or that are still active (467 volcanoes).

The main sources of data used for the realization of the map are: the NOAA Earthquake Data file (Whiteside, up to 2001), Current Plate Motions (De Mets et al., 1990, 1994), the CGMW/UNESCO Geological Map of the World (Bouysse et al., 2000), the ILP/USGS World Stress Map (Zoback et al., 1992), the Scripps/UCSD/GSC/ GEMCO/UTIG Digital Age Map of the Oceanic Floor (Müller et al., 1997), the Scripps/NOAA Marine Gravity Anomaly from Satellite Altimetry (Sandwell and Smith, 1995), and the Smithsonian Institution Holocene Volcanoes file (Smithsonian Institution, up to 2001).

\section{Representation of the seismicity}

According to the representation of the seismicity status of the recorded event (historical, instrumental before 1964, instrumental after 1963) and to the 5 categories of focal depths, the earthquakes are grouped in 11 columns, each of which is subdivided horizontally in three categories of magnitude/intensity (see Table).

In order to ensure legibility of the background information (area colours and structural features), three types of open symbol have been used to represent epicentres based on the recording mode: triangles for historical events (from $3000 \mathrm{BC}$ to AD 1900), lozenges for instrumental events from AD 1900 to 1963, and circles for more recent instrumental events from AD 1964 to 2001. The symbol size defines the magnitude range: small for 6.0-6.9, medium for 7.0-7.9, and large for $\geq 8.0$. In addition, the symbols representing instrumental seismic events are assigned five colours to differentiate the focal depth range: red for $0-35 \mathrm{~km}$, blue for $36-70 \mathrm{~km}$, green for $71-300$ $\mathrm{km}$, brown for $301-700 \mathrm{~km}$ and pink where the focal depth is unknown (this last case is relevant for both historical and instrumental events).

The 4 categories of focal-depth represented on the map are based on the overall structural and physical characteristics of the Earth's interior, approximate average layer thicknesses, and depths to the discontinuities. Focal depths from 0 to $35 \mathrm{~km}$ include the tectonosphere above the isostatic equilibrium level, with the different oceanic crusts, mid-oceanic divergent zones, the uppermost part of the subducion zone, and the continental crust of intermediate thickness between the Conrad and Moho discontinuities. Focal depths from 36 to $70 \mathrm{~km}$ include the oceanic lithosphere and rela-

\footnotetext{
* Intensity VIII corresponds to massive damages, destruction of the most vulnerable buildings and important damage to nearly all buildings.
} 


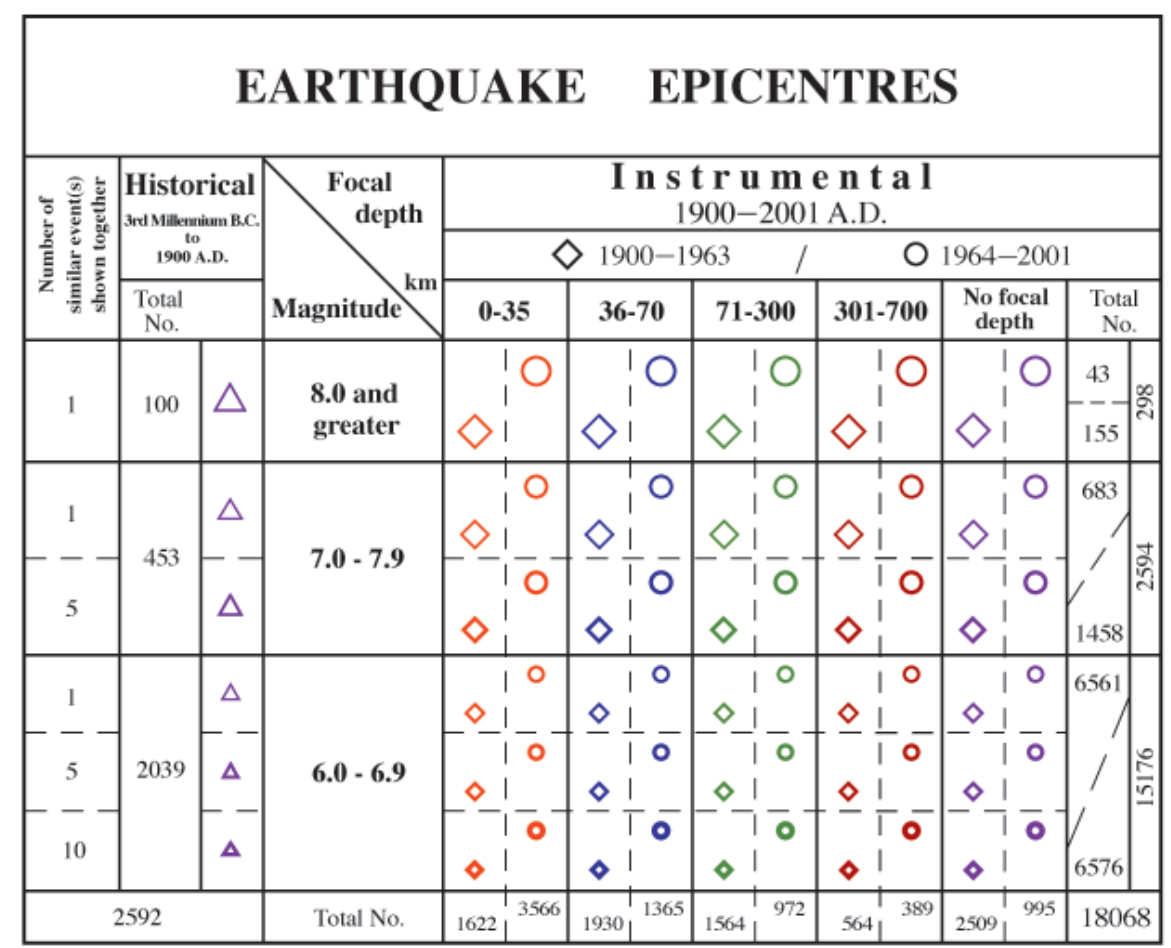

tively thick continental crusts beneath convergent mountain ranges. Focal depths from 71 to $300 \mathrm{~km}$ include the continental lithosphere, and collision and subduction zones. Finally, focal depths from 301 to $700 \mathrm{~km}$ comprise mobile and isostatic-adjustment zones related to the asthenosphere (upper mantle) and the deepest part of the subducted or Wadati/Benioff seismic zone.

To complete the earthquake information on the map, the number of events represented by one symbol at a given location is indicated by the symbol's line thickness: thin lines indicate a single event, medium lines five events and thick lines 10 events of similar magnitude and focal depth range and with epicentre locations that coincide or are very close in terms of map scale. Single earthquake events exist for all the magnitude ranges, clusters of five events are plotted only for magnitudes of 7.0-7.9, and clusters of 10 events are plotted only for magnitudes of 6.0-6.9. Statistics for each group of events are also given in the "Earthquake Epicentres" Table on the map legend (see above).

\section{Comments}

The map provides a general and worldwide view of the seismic zoning of the Earth and underlines particularly the neotectonic activity of the collisional Tethyan Alpine-Himalayan Belt, and the subduction-related Circum-Pacific Ring more complex on its western side with its succession of island arcs and back-arc basin than on its eastern one, characterized by its cordilleran system. About $30 \%$ of the major earthquakes are distributed along the neotectonically active Tethyan Alpine-Himalayan Belt, and about $70 \%$ along the CircumPacific Ring of continental margins/island arcs (43\% in the west and $27 \%$ in the east), with two-thirds of these being located in the northern hemisphere (as is also the case with the active and recent volcanoes) due mainly to the distribution of the continental masses. The distensive phenomena of the intra-continental rift such as the East African Rift system or the Baikal rift are also underlined, despite the relatively high level of magnitude discrimination chosen $(\geq 6.0)$ for the realization of the map. For the same reason, the widespread but generally rather low seismicity of the some $70,000 \mathrm{~km}$ long spreading axis system is, evidently, graphically under-represented on the map, whereas this seismicity was actually one of the elements that contributed to the elaboration of the plate-tectonics. Therefore, the axes of oceanic accretion (in blue on the map) and the segments of true transform faults (in red) can be considered as substitutes of the symbols representing this category of epicentres.

It is interesting to note the occurrence of some significant earthquakes in a continental intraplate context (see e.g. the Republic of Guinea or the Brazilian craton).

Let us recall that the earliest known earthquake event was in the Buyin Zahra district of Persia (now Iran) at lat. $35.60^{\circ} \mathrm{N}$, long. $49.90^{\circ} \mathrm{E}$. Archaeological excavations in the graveyard and mounds of Sagzabad indicate that a devastating earthquake in the third millennium BC destroyed settlements in the district. During the last hundred years or so (1900-2001), 298 earthquakes with a "catastrophic" magnitude of 8.0 or greater have been recorded. The strongest event ever recorded up to now occurred on May 22, 1960 in Lebu, Chile, and its magnitude was 9.5 (seismic moment). During the period AD 1964 to 2001, with its more technically advanced worldwide instrumental seismic network, the mean annual total of globally recorded earthquakes amounted to approximately 200 events of magnitude $\geq 6.0$, including some 180 events of magnitude $6.0-6.9,18$ events of magnitude 7.0-7.9, and 1 or 2 events of magnitude $\geq 8.0$.

The publication of the Seismotectonic Map of the World by the CGMW and UNESCO at the beginning of the third millennium AD is a significant contribution to worldwide scientific communities and educational institutions. Given the characteristics and frequency of earthquakes and their effects on society, it is of crucial importance to heighten awareness of these events and their secondary effects in the aim of improving prevention policies and safety measures. This educational project was conceived as a contribution to the United Nations - International Decade for Natural Disaster Reduction (UN-IDNDR), since superseded by the International Structure for Disaster Relief (ISDR).

The distributers of the Map are the CGMW and UNESCO. The retail price of the map is 42 Euros. The contact for ordering the map is either <www.cgmw.org> or <ccgm@ @lub-internet.fr>.

\section{Philippe Bouysse}

Former CGMW Secretary General

Abdolazim Haghipour

CGMW Vice-President for the Middle East 

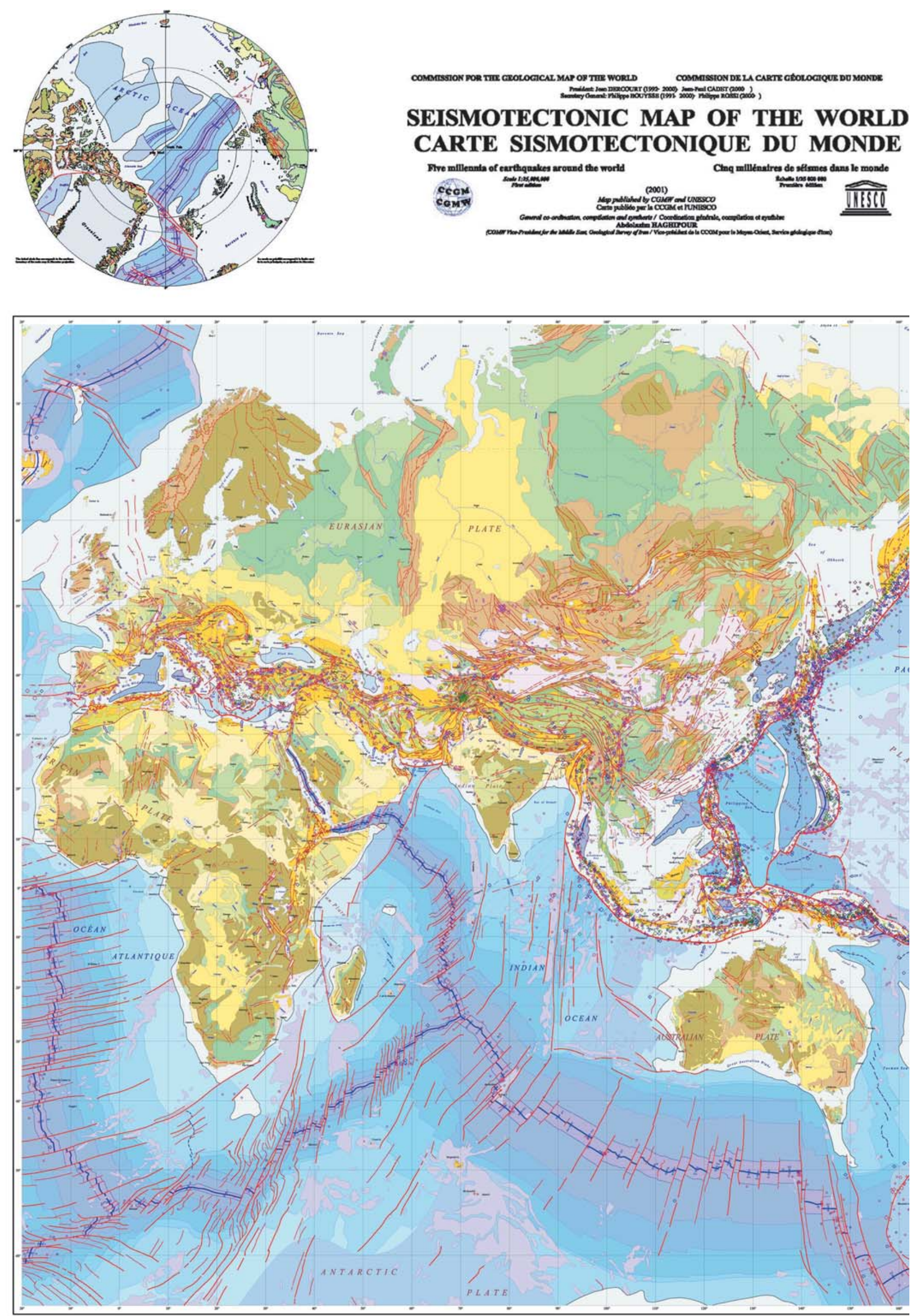

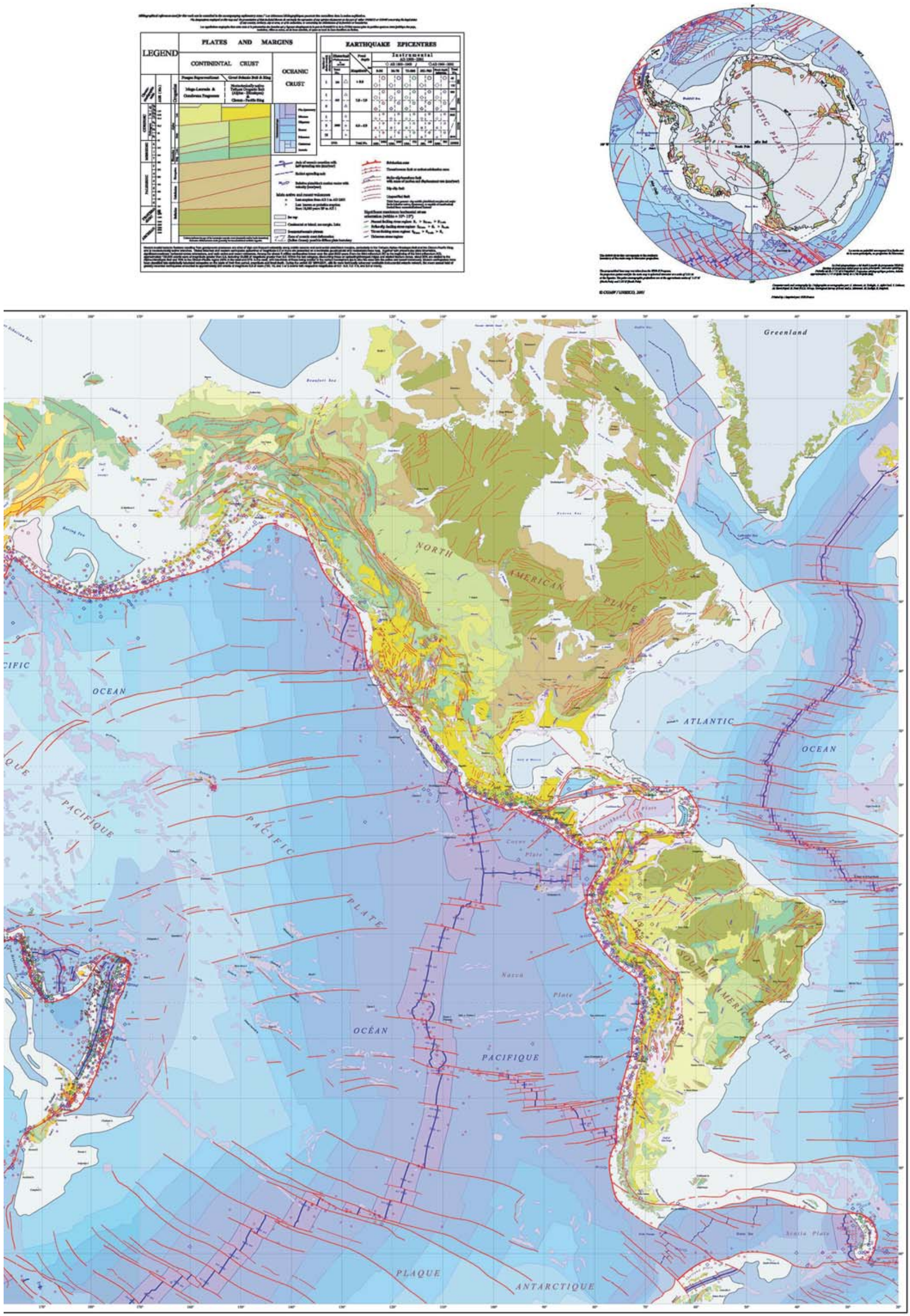